\title{
Fracture patterns and complications related to pedestrian-vehicle collision victims in a public Level-1 Trauma Centre ICU population
}

\author{
Bakkai $\mathrm{A}^{1}$, Hardcastle $\mathrm{TC}^{2}$, Sibanda $\mathrm{W}^{3}$ \\ 1 MBChB, HDipOrth(SA), FCOrth(SA); Registrar, Orthopaedics, University of KwaZulu-Natal \\ ${ }^{2}$ MBChB(Stell), MMed(Chir)(Stell), PhD(UKZN), FCS(SA); Trauma(HPCSA) Trauma ICU, Inkosi Albert Luthuli Central Hospital; Honorary Senior Lecturer, \\ Department of Surgery, University of KwaZulu-Natal \\ ${ }^{3} \mathrm{PhD}(\mathrm{IT})(\mathrm{NWU})$; Biostatics Unit, School of Nursing and Public Health, College of Health Science, University of KwaZulu-Natal, Durban, South Africa
}

Corresponding author: Dr Ali Bakkai, 27 Nordbury, 130 Gladys Mazibuko Road, Essenwood, Durban, 4001; email: alibakkai@yahoo.com; tel: 0812701076,0312075555

\begin{abstract}
Introduction: Death and injury associated with road traffic collisions are global phenomena that require urgent attention. Approximately 1.2 million people worldwide are killed each year. Pedestrian collisions remain one of the single largest causes of injury, disability, and death in the developing world and contribute significantly to trauma centre activity, especially in urban areas.
\end{abstract}

Materials and methods: The study aim was to describe the fracture patterns in pedestrians, and to highlight the epidemiology, spectrum, and outcomes of orthopaedic injuries identified in pedestrian vehicle collision (PVC) victims admitted to a major trauma intensive care unit (TICU). This retrospective analysis of 405 PVC victims, retrieved from an Ethics Approved Trauma Registry (BE360/13 and BE207/09) admitted to the TICU at Inkosi Albert Luthuli Central Hospital, Durban, South Africa, spans a six-year period from 2007 to 2012.

Results: Four hundred and five pedestrian-vehicle collision patients were admitted over the six-year study period. Missing data were found in two patients. The mean age was $25.8 \pm 17.49$ years, with 135 (33.3\%) female patients and 270 (66.7\%) males. One hundred and eleven patients were referred directly from the scene; the others were inter-hospital transfers. Two hundred and eighty-five patients had fractures and from this group, 63 (22\%) patients died in ICU. The most common fracture site was femur (122), followed by tibia (112) and pelvis (95). The mortality was related mainly to the age of the victims; none of the fractures were found to be associated directly with increased mortality.

Conclusion: Diverse fracture patterns are seen in PVC patients. The leading cause of death is head injury, followed by chest injury. Increased age of the patients was associated with increased mortality. The predominance of specific fractures, in specific sex and age groups, were noted, and some fractures were found to be associated with more complications; however, none of the fractures were linked directly to mortality.

Level of evidence: Level 4

Key words: trauma, pedestrian, fracture, ICU outcome, complications

Citation: Bakkai A, Hardcastle TC, Sibanda W. Fracture patterns and complications related to pedestrian-vehicle collision victims in a public Level-1 Trauma Centre ICU population. SA Orthop J 2018;17(2):28-34. http://dx.doi.org/10.17159/2309-8309/2018/v17n2a5

Editor: Prof Anton Schepers, University of the Witwatersrand

Received: February 2017 Accepted: October $2017 \quad$ Published: March 2018

Copyright: @ 2018 Bakkai A, et al. This is an open-access article distributed under the terms of the Creative Commons Attribution Licence, which permits unrestricted use, distribution and reproduction in any medium, provided the original author and source are credited.

Funding: No financial support was received for this study.

Conflict of interest: The authors have no conflicts of interest to declare. 


\section{Introduction}

Death and injury associated with road traffic crashes are global phenomena that require urgent attention. ${ }^{1}$ Approximately 1.2 million people worldwide are killed each year resulting from road traffic crashes. ${ }^{2}$ Pedestrian collisions are noted to be one of the single largest causes of injury, disability and death in the developing world. ${ }^{2-4}$ Pedestrian-vehicle collisions (PVCs) contribute significantly to trauma centre activity, especially in urban areas. ${ }^{1}$ Epidemiologic studies may allow for further understanding of risk factors involved in roadside pedestrian injuries. ${ }^{5}$ Previous studies have demonstrated the impact of geographical and demographic factors on PVCs in specific cities, mainly in the USA, by using the age as a predictor of the outcome of the patients. ${ }^{5-7}$

The aim of this study was to investigate the fracture patterns, epidemiology, spectrum and clinical outcomes of pedestrians involved in PVCs. The outcomes in this study were death or survival following admission to a trauma intensive care unit (TICU) at Inkosi Albert Luthuli Central Hospital (IALCH). It has been previously reported that up to $50 \%$ of patients admitted to the TICU at IALCH are as a result of pedestrian collisions. ${ }^{8}$

\section{Materials and methods}

The study was performed in the TICU (Level 1 Centre) at IALCH, Durban, South Africa. The target group for this study was PVC victims admitted to TICU (or those who died in the resuscitation bay), in the period March 2007 until December 2012.

After obtaining ethical approval (UKZN BREC - BE360/13), a retrospective chart review was undertaken, using the data from the BREC Class Approved (BE207/09) electronic patient record system.

\section{Study design}

The pedestrian data obtained included: age, sex, fracture pattern, the length of stay, other non-orthopaedic injuries, complications and whether the patient was transferred directly from the accident scene or from another hospital. The severity of injuries was assessed using the Injury Severity Score (ISS). ${ }^{9}$ Almost all patients had CT scan angiograms, except patients who died in the resuscitation room. All fractures identified were reviewed and included, irrespective of whether they were single or multiple fractures. The study analysed the epidemiology and fracture patterns. In-hospital morbidity and mortality associated with orthopaedic injuries were the main outcome measures, with the intent to identify fractures associated with a higher risk of death.

\section{Statistical analyses}

Data analysis was performed using IBM SPSS version 24 (Armonk, NY, USA) and SAS version 9.0 (SAS Institute, Cary, NC). Continuous variables were summarised using mean \pm standard deviation (SD), and medians and interquartile ranges (IQR) were used for highly skewed data. Categorical variables were summarised using proportions and percentages. Proportions and categorical variables were compared using Pearson's chi-square test and Fisher's exact test as appropriate. A multivariate logistic regression model was used to assess the association between different predictor variables and clinical outcome and to identify potential risk factors. An odds ratio for each variable was calculated. A p-value $<0.05$ was accepted as indicative of statistical significance.

\section{Results}

Between March 2007 and December 2012, 405 patients were admitted as PVC victims in the trauma unit at IALCH. Missing data were found in two participants $(0.5 \%)$. A total of 403 patients were included in the logistic regression. One hundred and thirty-five (33.3\%) of the patients were female (95\% confidence interval [Cl] 28.0-37.9) and $270(66.7 \%)$ were male $(95 \% \mathrm{Cl} 62.11-71.29 \%)$. A total of 94 (23.2\%) patients died due to their injuries $(95 \% \mathrm{Cl} 19.09-27.31)$, 309 (76.3\%) survived (95\% Cl 72.16-80.44) and in two (0.5\%) their

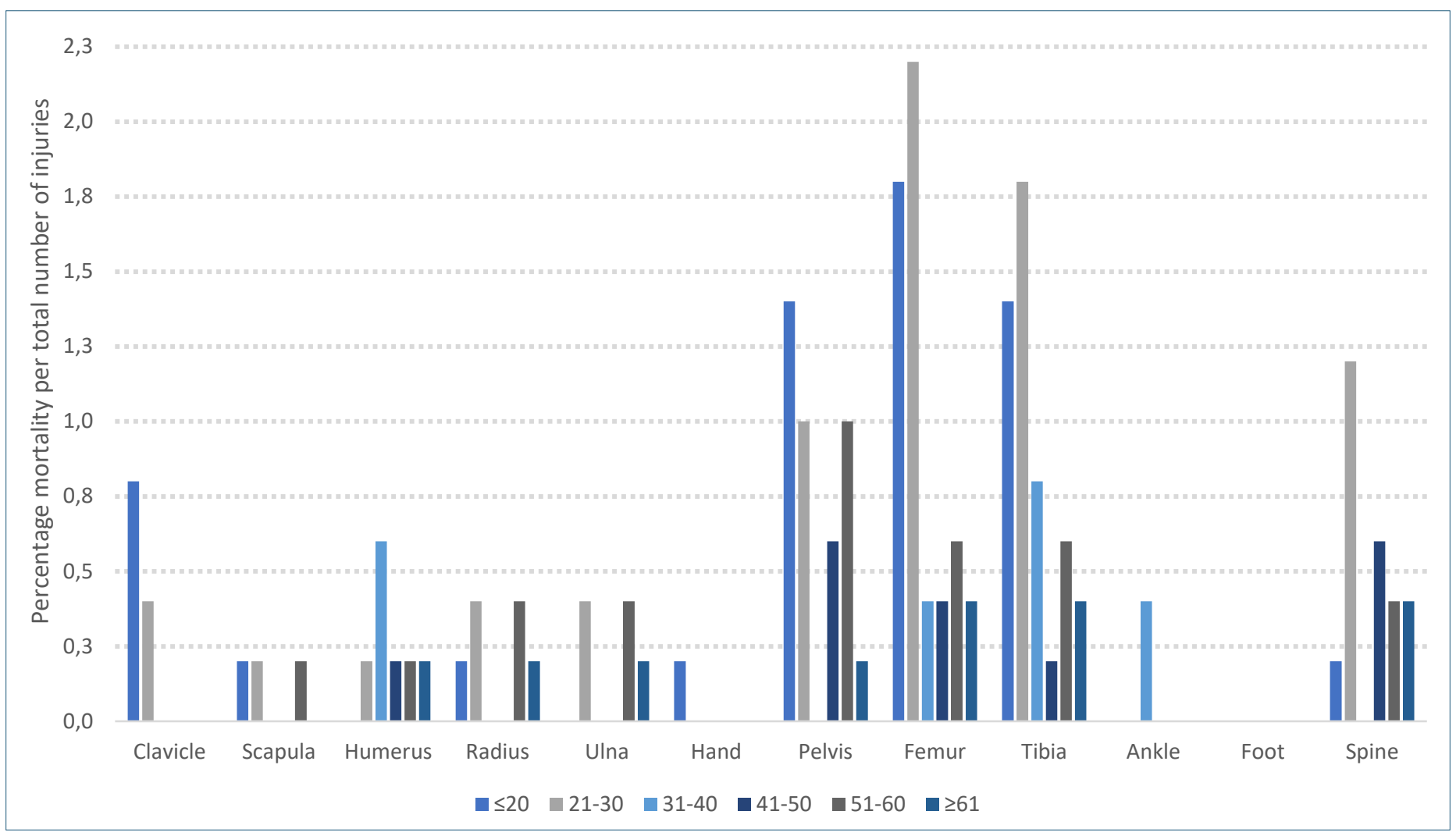

Figure 1. Age group-based mortality per injury 
Table I: Descriptive statistics

\begin{tabular}{|c|c|c|c|c|c|c|}
\hline \multicolumn{2}{|c|}{ Independent variables } & \multicolumn{3}{|c|}{ Clinical outcome } & $\begin{array}{l}\text { Total } \\
\text { n (\%) }\end{array}$ & ${ }^{*} \mathrm{p}$-value \\
\hline \multirow{3}{*}{ Gender } & Female & 29 (30.9) & 105 (34) & $1(50)$ & & \\
\hline & Male & 65 (69.1) & $204(66)$ & $1(50)$ & & \\
\hline & Total & 94 (100) & 309 (100) & $2(100)$ & 405 (100) & 0.573 \\
\hline \multirow[t]{7}{*}{ Age } & $\leq 20$ & 33 (35.1) & 122 (39.5) & $0(0)$ & & \\
\hline & $21-30$ & $23(24.5)$ & $100(32.4)$ & $1(50)$ & & \\
\hline & $31-40$ & $9(9.6)$ & 45 (14.6) & $1(50)$ & & \\
\hline & $41-50$ & 10 (10.6) & $22(7.1)$ & $0(0)$ & & \\
\hline & $51-60$ & $8(8.5)$ & $11(3.6)$ & $0(0)$ & & \\
\hline & $>61$ & $11(11.7)$ & $9(2.9)$ & $0(0)$ & & \\
\hline & Total & 94 & 309 & $2(100)$ & 405 (100) & 0.0121 \\
\hline \multirow[t]{3}{*}{ Clavicle } & 0 & 88 (93.6) & 293 (94.8) & $1(50)$ & & \\
\hline & 1 & $6(6.4)$ & $16(5.2)$ & $1(50)$ & & \\
\hline & Total & $94(100)$ & $309(100)$ & $2(100)$ & 405 (100) & 0.652 \\
\hline \multirow[t]{3}{*}{ Scapula } & 0 & $91(96.8)$ & 297 (96.1) & $2(100)$ & & \\
\hline & 1 & $3(3.2)$ & $12(3.9)$ & $0(0)$ & & \\
\hline & Total & 94 (100) & $309(100)$ & $2(100)$ & 405 (100) & 0.756 \\
\hline \multirow[t]{3}{*}{ Humerus } & 0 & 87 (96.6) & 281 (90.9) & $2(100)$ & & \\
\hline & 1 & $7(7.4)$ & $28(9.1)$ & $0(0)$ & & \\
\hline & Total & $94(100)$ & 309 (100) & $2(100)$ & 405 (100) & 0.626 \\
\hline \multirow[t]{3}{*}{ Radius } & 0 & 88 (93.6) & $292(94.5)$ & $2(100)$ & & \\
\hline & 1 & $6(6.4)$ & $17(5.5)$ & $0(0)$ & & \\
\hline & Total & $94(100)$ & 309 (100) & $2(100)$ & 405 (100) & 0.747 \\
\hline \multirow[t]{3}{*}{ Ulna } & 0 & 89 (94.7) & 288 (93.2) & $2(100)$ & & \\
\hline & 1 & $5(5.3)$ & $21(6.8)$ & $0(0)$ & & \\
\hline & Total & $94(100)$ & 309 (100) & $2(100)$ & 405 (100) & 0.610 \\
\hline \multirow[t]{3}{*}{ Hand } & 0 & 93 (98.9) & 307 (99.4) & $2(100)$ & & \\
\hline & 1 & $1(1.06)$ & $2(0.6)$ & $0(0)$ & & \\
\hline & Total & $94(100)$ & 309 (100) & $2(100)$ & $405(100)$ & 0.681 \\
\hline \multirow[t]{3}{*}{ Pelvis } & 0 & $73(77.7)$ & 235 (75.1) & $2(100)$ & & \\
\hline & 1 & 21 (22.3) & 74 (23.9) & $0(0)$ & & \\
\hline & Total & $94(100)$ & 309 (100) & $2(100)$ & $405(100)$ & 0.748 \\
\hline \multirow[t]{3}{*}{ Femur } & 0 & 65 (69.1) & 216 (69.9) & $2(100)$ & & \\
\hline & 1 & 29 (30.9) & $93(30.1)$ & $0(0)$ & & \\
\hline & Total & $94(100)$ & 309 (100) & $2(100)$ & $405(100)$ & 0.889 \\
\hline \multirow[t]{3}{*}{ Tibia } & 0 & 68 (72.3) & 223 (72.2) & $2(100)$ & & \\
\hline & 1 & $26(27.7)$ & 86 (27.8) & $0(0)$ & & \\
\hline & Total & 94 (100) & 309 (100) & $2(100)$ & $405(100)$ & 0.974 \\
\hline \multirow[t]{3}{*}{ Ankle } & 0 & 92 (97.9) & $292(94.5)$ & $2(100)$ & & \\
\hline & 1 & $2(2.1)$ & $17(5.5)$ & $0(0)$ & & \\
\hline & Total & $94(100)$ & 309 (100) & $2(100)$ & 405 (100) & 0.177 \\
\hline \multirow[t]{3}{*}{ Foot } & 0 & 94 (100) & 307 (99.4) & $2(100)$ & & \\
\hline & 1 & $0(0.0)$ & $2(0.6)$ & $0(0)$ & & \\
\hline & Total & 94 (100) & 309 (100) & $2(100)$ & $405(100)$ & 0.434 \\
\hline \multirow[t]{3}{*}{ Spine } & 0 & $80(85.1)$ & 279 (90.3) & $2(100)$ & & \\
\hline & 1 & $14(14.9)$ & $30(9.7)$ & $0(0)$ & & \\
\hline & Total & 94 (100) & 309 & $2(100)$ & 405 (100) & 0.158 \\
\hline
\end{tabular}

${ }^{*}$ chi-squared test

clinical outcome was not recorded (95\% Cl 0.19-1.19). The median ISS among all patients was 29 (IQR: 18-36), and the mean age was $25.8 \pm 17.49$ years. One hundred and eleven (27.4\%) patients were transferred directly from the scene, and the rest $(n=294,72.6 \%)$ from other hospitals for advanced care post-resuscitation.
All the patients had either CT angiogram or a combination of trauma $X$-rays and CT scan, to evaluate multiple organ injuries, except patients who died in the resuscitation room. The median hospital stay was eight days (IQR: 9-15).

The number of patients found to have orthopaedic injuries was 285 , of whom 63 demised, with a mortality rate of $22 \%$. In this group, 
Table II: Odds ratio for all variables

\begin{tabular}{|c|c|c|c|c|c|c|c|}
\hline \multicolumn{4}{|c|}{ Odds ratio of living after accident } & \multicolumn{4}{|c|}{ Odds ratio of dying after accident } \\
\hline $\begin{array}{l}\text { Independent } \\
\text { variable }\end{array}$ & Odds ratio & $\begin{array}{c}95 \% \\
\text { Confidence } \\
\text { interval }\end{array}$ & p-value & $\begin{array}{l}\text { Independent } \\
\text { variable }\end{array}$ & Odds ratio & $\begin{array}{c}95 \% \\
\text { Confidence } \\
\text { interval }\end{array}$ & p-value \\
\hline Age & 0.741 & $0.629-0.871$ & 0.0003 & Age & 1.350 & $1.148-1.589$ & 0.0003 \\
\hline Sex & 0.961 & $0.564-1.613$ & 0.8806 & Sex & 1.041 & $0.620-1.773$ & 0.8806 \\
\hline Clavicle & 0.790 & $0.298-2.352$ & 0.6491 & Clavicle & 1.266 & $0.425-3.354$ & 0.6491 \\
\hline Scapula & 1.425 & $0.390-6.914$ & 0.6190 & Scapula & 0.702 & $0.145-2.562$ & 0.6190 \\
\hline Humerus & 1.490 & $0.605-4.152$ & 0.4113 & Humerus & 0.671 & $0.241-1.654$ & 0.4113 \\
\hline Radius & 0.446 & $0.095-2.028$ & 0.2885 & Radius & 2.243 & $0.493-10.48$ & 0.2885 \\
\hline Ulna & 2.588 & $0.594-14.35$ & 0.2362 & Ulna & 0.386 & $0.070-1.685$ & 0.2362 \\
\hline Hand & 0.567 & $0.051-12.70$ & 0.6520 & Hand & 1.765 & $0.079-19.63$ & 0.6520 \\
\hline Pelvis & 1.153 & $0.653-2.10$ & 0.6311 & Pelvis & 0.867 & $0.477-1.531$ & 0.6311 \\
\hline Femur & 0.849 & $0.501-1.46$ & 0.5477 & Femur & 1.178 & $0.686-1.998$ & 0.5477 \\
\hline Tibia & 1.078 & $0.629-1.89$ & 0.7880 & Tibia & 0.928 & $0.530-1.589$ & 0.7880 \\
\hline Ankle & 2.990 & $0.808-19.46$ & 0.1557 & Ankle & 0.334 & $0.051-1.238$ & 0.1557 \\
\hline Spine & 0.660 & $0.327-1.39$ & 0.2569 & Spine & 1.515 & $0.721-3.063$ & 0.2569 \\
\hline
\end{tabular}

head injury was present in 36 patients (57\%), while chest injury was noted in 13 patients (20\%). Nineteen of those patients died during resuscitation (6.6\%).

Using the chi-square test, age was the only independent variable with a statistically significant association with the clinical outcome $(p$-value $=0.0121)$. However, no bone injuries had a statistically significant association with the outcome $(p>0.05)$ in all fracture groups as illustrated in Table I. Using a binary logistic regression model, the odds of dying from injuries for older patients were 1.35 times higher than younger patients (OR 1.35, 95\% Cl 1.148-1.589), and the odds ratio (OR) was statistically significant $(p$-value $=0.0003)$. The ORs for some fractures were not statistically significant with a wide $\mathrm{Cl}$ indicating a low level of precision. On the other hand, the OR of injuries to spine, clavicle, and femur resulted in $1.515,1.266$ and 1.178 times the likelihood of dying. Though the
95\% Cls (0.721-3.063, 0.425-3.354, and 0.686-1.998) respectively indicate high precision in OR, these OR were not statistically significant (Table II). The mortality rate in males was $24 \%$ and in females $22 \%$. The most common fracture identified was femur fracture $(n=122,23.4 \%)$, followed by tibia ( $n=113,21.7 \%)$, and pelvis $(n=95,18.2 \%)$. Those fractures involved almost all age groups with notable predominance of the femur and tibia below the age of 30 years as illustrated in Figure 1. The sex-related injuries (Figure 2) show that females with fractured clavicle, scapula or pelvis have a slightly higher mortality, whereas in males, only those with fractured spine were noted to have higher mortality.

The most common cause of death, according to hospital records, among all pedestrians was head injury ( $n=56,60 \%)$, followed by chest injury $(n=17,18 \%)$, while others included pulmonary embolism, retroperitoneal haematoma, crush injury to the pelvis, septic shock,

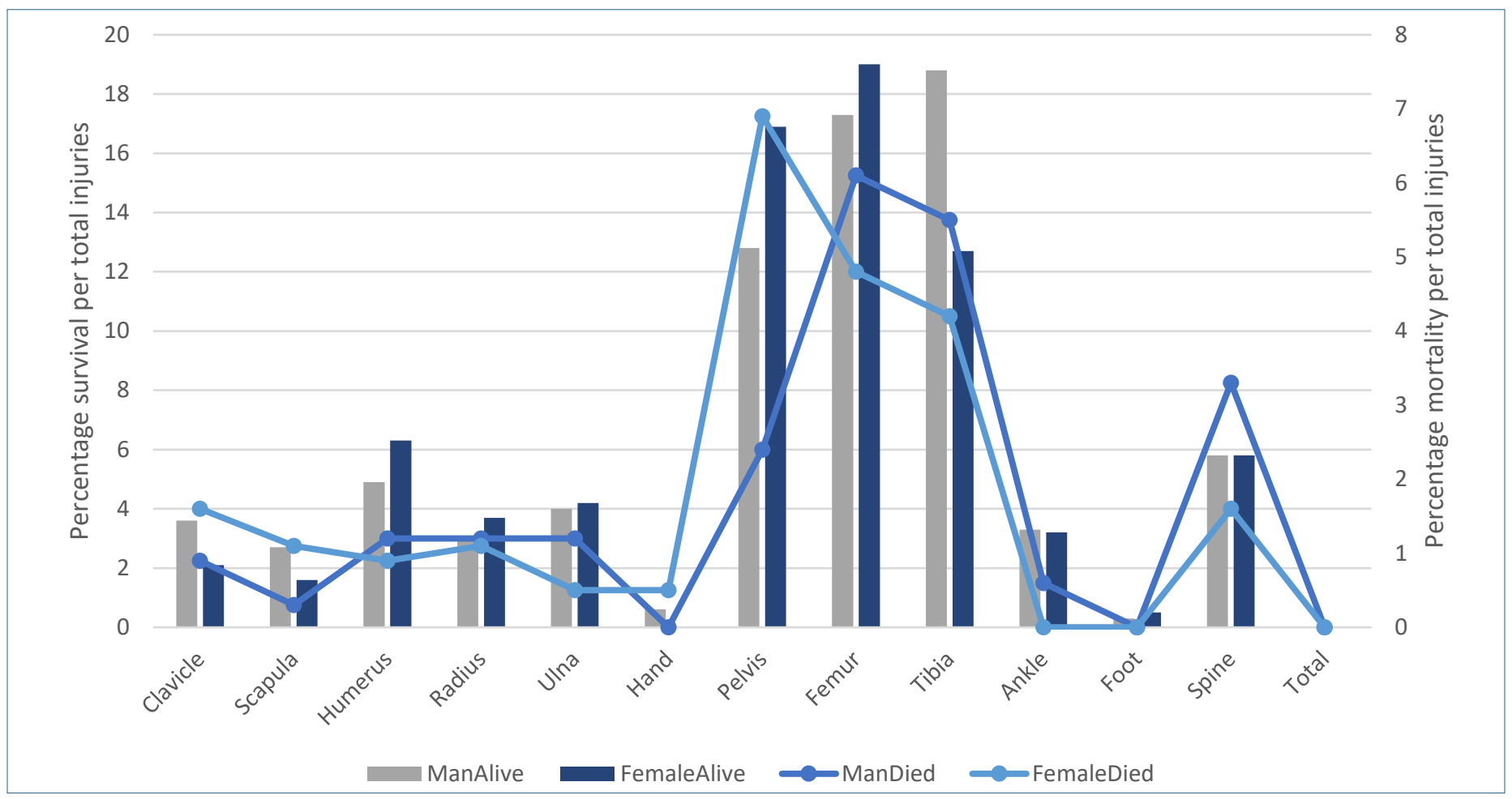

Figure 2. Sex-grouped injuries 


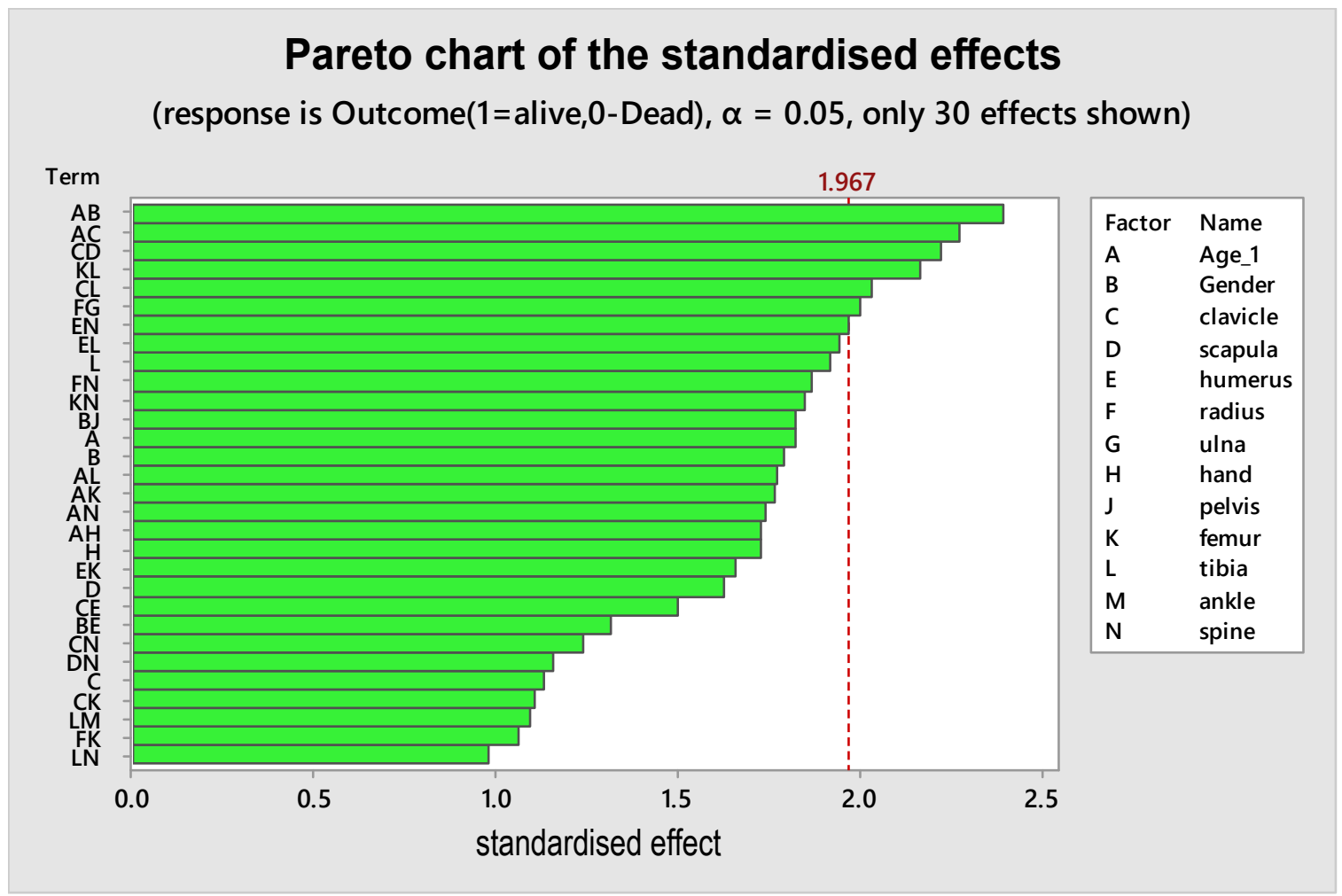

Figure 3. Combined factors effect

myocardial infarction, ruptured uterus, liver and spleen injuries, aortic arch injury, and ruptured diaphragm ( $n=21,22 \%)$. Among the fatalities, the oldest was 82 years of age, who died during resuscitation, while the youngest was 2 years old, who died due to a head injury.

The fracture combinations that were seen included femur and tibia (21 injured, 6 dead), pelvis and femur (14 injured, 3 dead). Using a Fisher's exact test to determine whether there is an association between combined fractures without head and chest injuries and the same combined fractures with head and chest injuries, a conclusion was that the combined fractures (with and without head and chest injuries) are independent of clinical outcome (mortality), i.e. there was no association between femur and tibia injuries in isolation or with head injury, chest injury, and both head and chest injury ( $p$-value $=0.1322,0.7063,0.2507)$ respectively. A similar observation was made for pelvis and femur alone, or with a head injury, chest injury and both head and chest injury ( $p$-value $=0.8658,0.4795,0.8298$ ) respectively (Table III). However, using a two-sample test to compare the differences in proportions of deaths among femur and tibia injuries (femur+tibia (12\%) vs femur+tibia+head (50\%), femur+tibia (12\%) vs femur+tibia+chest (20\%), femur+tibia (12\%) vs femur+tibia+head+ chest (50\%), the result indicated statistically significant differences at $p<0.0001$, which means that including head or chest or both tended to result in increased mortality. The commonest complications noted among survivors (Table $M$ ) included: amputations $(n=9,3 \%)$, nosocomial pneumonia $(n=5,1.6 \%)$, line sepsis $(n=3,1 \%)$, acute kidney injury $(n=3,1 \%)$, compartment syndrome $(n=3,1 \%)$, and small bowel obstruction $(n=1,0.3 \%)$. The commonest fracture noticed to be associated with those complications was the tibia, i.e. all patients who had compartment syndrome, two patients with acute kidney injury, all patients with line sepsis, two patients with nosocomial

Table III: Fractures combinations, associations with head and chest injuries

\begin{tabular}{|c|c|c|c|}
\hline Injury combination & $\begin{array}{l}\text { Outcome: } \\
\text { Alive }\end{array}$ & Dead & P-value \\
\hline Femur+tibia & $7(88 \%)$ & $1(12 \%)$ & \multirow{2}{*}{0.1322} \\
\hline Femur+tibia+head & $3(50 \%)$ & $3(50 \%)$ & \\
\hline Femur+tibia & $7(88 \%)$ & $1(12 \%)$ & \multirow{2}{*}{0.7063} \\
\hline Femur+tibia+chest & $4(80 \%)$ & $1(20 \%)$ & \\
\hline Femur+tibia & $7(88 \%)$ & $1(12 \%)$ & \multirow{2}{*}{0.2507} \\
\hline Femur+tibia+head+chest & $1(50 \%)$ & $1(50 \%)$ & \\
\hline Pelvis+femur & $3(75 \%)$ & $1(25 \%)$ & \multirow{2}{*}{0.8658} \\
\hline Pelvis+femur+head & $4(80 \%)$ & $1(20 \%)$ & \\
\hline Pelvis+femur & $3(75 \%)$ & $1(25 \%)$ & \multirow{2}{*}{0.4795} \\
\hline Pelvis+femur+chest & $2(100)$ & $\mathrm{O}(0 \%)$ & \\
\hline Pelvis+femur & $3(75 \%)$ & $1(25 \%)$ & \multirow{2}{*}{0.8298} \\
\hline Pelvis+femur+head+chest & $2(67 \%)$ & $1(33 \%)$ & \\
\hline
\end{tabular}

\footnotetext{
*Fisher's exact test
} 
Table IV. Complications among survivals

\begin{tabular}{|c|c|c|}
\hline Complication & Number & Fracture \\
\hline Small bowel obstruction & 1 & Fracture femur \\
\hline Compartment syndrome & 3 & $\begin{array}{l}\text { Fracture tibia, pelvis } \\
\text { Fracture tibia, scapula } \\
\text { Fracture tibia }\end{array}$ \\
\hline Acute kidney injury & 3 & $\begin{array}{l}\text { Fracture pelvis } \\
\text { Fracture femur, tibia } \\
\text { Fracture tibia }\end{array}$ \\
\hline Line sepsis & 3 & $\begin{array}{l}\text { Fracture tibia, clavicle, spine } \\
\text { Fracture tibia } \\
\text { Fracture tibia }\end{array}$ \\
\hline Nosocomial pneumonia & 5 & $\begin{array}{l}\text { Fracture tibia, pelvis } \\
\text { Fracture spine, pelvis, scapula } \\
\text { Fracture radius } \\
\text { Fracture tibia, clavicle } \\
\text { Fracture clavicle }\end{array}$ \\
\hline Amputation & 9 & $\begin{array}{l}\text { Six patients with fracture femur and tibia, one patient with foot fracture, one patient } \\
\text { with femur fracture, one patient with femur and pelvis fracture }\end{array}$ \\
\hline
\end{tabular}

pneumonia, six patients who had amputations, initially had a tibia fracture.

Using a Pareto chart (Figure 3), to distinguish the few most important factors from the many unimportant predictive variables, indicated that the following two-factor interactions accounted for $80 \%$ of the observed clinical outcomes: sex*age, age ${ }^{*}$ clavicle, clavicle*scapula, femur*tibia, clavicle*tibia, and radius ${ }^{*} u l n a$. None of the individual main effects constituted the $20 \%$ that resulted in the $80 \%$ of the observed clinical outcomes. In general, a Pareto chart provides an illustration of the Pareto Principle, which asserts that $80 \%$ of the observed outcome is produced by $20 \%$ of the input variables.

\section{Discussion}

This epidemiological retrospective study investigates the patterns of fractures and complications observed among PVCs admitted to a tertiary TICU. It also highlights the effects of other factors including age and sex. Furthermore, it describes the predominance of specific fractures in different age groups.

PVCs are responsible for a substantial portion of overall road traffic accidents, with the highest fatality percentage among all road users attributed to pedestrians. ${ }^{10}$ Many studies have looked at the demographics and prevention aspects of pedestrian injuries in both developed and developing countries. ${ }^{11-13}$

The present study describes in depth different fracture patterns seen in PVC victims, starting from the clavicle to the foot. From this study, a diversity of fractures is noted among the pedestrians, with different patterns in each age and sex groups. Of note is the presence of femur and tibia fractures in all age groups with specific predominance among the victims younger than 30 years, and notably higher mortality in females with pelvis fracture. An important finding from our study is that none of the fractures, either isolated or combined, has a direct effect on mortality, but when head and chest are added together, a trend towards mortality is noticed. However, some fractures are noted to be associated with a higher morbidity, an example is the association between tibia fracture and in-hospital complications.

The findings of this study and previous reports show that fracture patterns in pedestrians involve mainly the lower extremity, specifically femur, followed by tibia and pelvis, which is attributed to the position of the knee joint, level of the pelvis and in relation to what part of the vehicle collides with the pedestrian. $7,14,15$

The present study confirmed the finding of previous studies about the effect of age on mortality, relating that to the anatomical and physiological changes associated with an increase in age, as well as comorbidities and osteoporosis making the elderly more fragile with a subsequent high death rate. ${ }^{16}$

Head injury is confirmed by this study $(60 \%)$ to be in concordance with previous research as the main cause of fatality among pedestrians and is followed by chest injuries at 18\%.15,17-19 Additionally, the mortality rate $(23.2 \%)$ in our cohort is consistent with a previous study. ${ }^{20}$ However, in the current cohort, with $67 \%$ male and $33 \%$ female, the mortality rate among men was $24 \%$ which is different from previous reports. ${ }^{21,22}$ Reith et al. reported in their study of 4435 pedestrian victims, similar findings in some aspects, including the association between pedestrian trauma and body parts involved, higher ISS, and subsequently higher mortality in PVC victims.

Epidemiological studies may allow for a better understanding of the injury pattern, length of stay, complications, as well as the mortality in roadside pedestrian victims. Furthermore, this type of study can be used for educational efforts, triggering the trauma team to expect the injury profile, or predicted severity associated with PVCs, which may improve the initial trauma management, and the outcome. Such studies can be used to modify the physical and social environments of the transportation system and to prevent further escalation of the pedestrian collision pandemic.

This study has limitations considering it is a retrospective study, and does not include a comparison with injury patterns and outcomes of vehicle-occupant admissions. However, the strength of the study results from the large sample size, derived from a legible electronic database with all clinical detail captured on standardised templates. It is also the first study to describe in detail the fracture patterns in those patients with severe injury.

\section{Conclusion}

In conclusion, this study described in detail all fracture patterns seen in PVC victims, including single and combined fractures, and it validated a clinically known fact, namely the effect of age on the outcomes of this group. The mortality is related mainly to head injury followed by chest injuries. Lower limb fractures are more frequent, but no specific fractures are associated with increased mortality.

\section{Ethical approval}

Ethical approval was obtained from the University BREC ethics committee and the KwaZulu-Natal Department of Health prior to the commencement of data collection. 


\section{References}

1. Martin ND, Grabo DJ, Tang L, Sullivan J, Kaulback KR, Weinstein $\mathrm{MS}$, et al. Are roadside pedestrian injury patterns predictable in a densely populated, urban setting? J Surg Res. 2010;163(2):323-26.

2. Aidoo EN, Amoh-Gyimah R, Ackaah W. The effect of road and environmental characteristics on pedestrian hit-and-run accidents in Ghana. Accid Anal Prev. 2013;53:23-27.

3. Hijar M, Trostle J, Bronfman M. Pedestrian injuries in Mexico: a multi-method approach. Soc Sci Med (1982). 2003;57(11):2149-59.

4. Sullman MJ, Gras ME, Font-Mayolas S, Masferrer L, Cunill M, Planes M. The pedestrian behaviour of Spanish adolescents. J Adolesc. 2011;34(3):531-39.

5. Lascala EA, Gerber D, Gruenewald PJ. Demographic and environmental correlates of pedestrian injury collisions: a spatial analysis. Accid Anal Prev. 2000;32(5):651-58.

6. Harruff RC, Avery A, Alter-Pandya AS. Analysis of circumstances and injuries in 217 pedestrian traffic fatalities. Accid Anal Prev. 1998;30(1):11-20.

7. Kong LB, Lekawa M, Navarro RA, McGrath J, Cohen M, Margulies $\mathrm{DR}$, et al. Pedestrian-motor vehicle trauma: an analysis of injury profiles by age. J Am Coll Surg. 1996;182(1):17-23.

8. Cheddie S, Muckart DJ, Hardcastle TC, Den Hollander D, Cassimjee $\mathrm{H}$, Moodley S. Direct admission versus inter-hospital transfer to a level I trauma unit improves survival: an audit of the new Inkosi Albert Luthuli Central Hospital trauma unit. S Afr Med J. 2011;101(3):176-78.

9. Copes WS, Champion HR, Sacco WJ, Lawnick MM, Keast SL, Bain LW. The Injury Severity Score revisited. J Trauma. 1988;28(1):69-77.

10. Toroyan T. Global status report on road safety. Inj Prev. 2009;15(4):286.

11. Fredriksson R, Zhang L, Bostrom O, Yang K. Influence of impact speed on head and brain injury outcome in vulnerable road user impacts to the car hood. Stapp Car Crash J. 2007;51:155-67.
12. Zhang G, Cao L, Hu J, Yang KH. A field data analysis of risk factors affecting the injury risks in vehicle-to-pedestrian crashes. Ann Adv Automot Med. 2008;52:199-214

13. Al-Shammari N, Bendak S, Al-Gadhi S. In-depth analysis of pedestrian crashes in Riyadh. Traffic Inj Prev. 2009;10(6):552-59.

14. Maki T, Kajzer J, Mizuno K, Sekine Y. Comparative analysis of vehicle-bicyclist and vehicle-pedestrian accidents in Japan. Accid Anal Prev. 2003;35(6):927-40.

15. Toro K, Hubay M, Sotonyi P, Keller E. Fatal traffic injuries among pedestrians, bicyclists and motor vehicle occupants. Forensic Sci Int. 2005;151(2-3):151-56.

16. Johnson CL, Margulies DR, Kearney TJ, Hiatt JR, Shabot MM. Trauma in the elderly: an analysis of outcomes based on age. Am Surg. 1994;60(11):899-902.

17. Takahashi $Y$, Kikuchi $Y$, Konosu A, Ishikawa H. Development and validation of the finite element model for the human lower limb of pedestrians. Stapp Car Crash J. 2000;44:335-55.

18. Al-Ghamdi AS. Pedestrian-vehicle crashes and analytical techniques for stratified contingency tables. Accid Anal Prev. 2002;34(2):205-14.

19. Pruthi N, Ashok M, Kumar VS, Jhavar K, Sampath S, Devi BI. Magnitude of pedestrian head injuries \& fatalities in Bangalore, south India: a retrospective study from an apex neurotrauma center. Indian $J$ Med Res. 2012;136(6):1039-43.

20. Brainard BJ, Slauterbeck J, Benjamin JB, Hagaman RM, Higie S. Injury profiles in pedestrian motor vehicle trauma. Ann Emerg Med. 1989;18(8):881-83.

21. Reith G, Lefering R, Wafaisade A, Hensel KO, Paffrath T, Bouillon B, et al. Injury pattern, outcome and characteristics of severely injured pedestrian. Scand J Trauma Resusc Emerg Med. 2015;23:56.

22. Zhao H, Yin Z, Yang G, Che X, Xie J, Huang W, et al. Analysis of 121 fatal passenger car-adult pedestrian accidents in China. J Forensic Leg Med. 2014;27:76-81. 